\title{
Green Performance Contracting Strategy for Highway Construction Projects
}

Xinyuan Zhu

University of Maryland,

College Park, MD

zxyemily@gmail.com
DOI 10.5592/otmcj.2014.3.7

Research paper
Qingbin Cui

Department of Civil and

Environmental Engineering at

University of Maryland College Park

cui@umd.edu
Hakob Gevorg Avetisyan

Department of Civil and

Environmental Engineering at

California State University Fullerton

havetisyan@fullerton.edu

\section{Keywords}

Green Performance

Contracting, Climate

Change, Highway

Construction
WITH THE GROWING AWARENESS OF SUSTAINABILITY AND GLOBAL CLIMATE CHANGE, STATE HIGHWAY AGENCIES ARE TAKING ESSENTIAL STEPSTO REDUCECARBONEMISSIONSFROM HIGHWAYINFRASTRUCTURE ON A LIFE CYCLE BASIS. While much is known regarding climate change mitigation and adaption strategies during highway operation, very little is understood about how climate change issues should be integrated into highway planning, delivery, and construction processes. This paper presents the current contracting practice for addressing the climate change issues. A Green Performance Contracting (GPC) framework is defined in this paper. Four levels of the GPC strategies are identified and discussed, namely, material related strategies, equipment and energy efficiency related strategies, green life-cycle strategies, and clean energy development strategies. Furthermore, a survey of the GPC practices of U.S. state DOTs is conducted, and strategies addressed by different states aligned with the four levels are also discussed. Finally, a Data Envelopment Analysis (DEA) model is proposed together with the evaluation criteria to assist state highway agencies in better incorporating green and sustainability into their project delivery processes. The evaluation criteria mainly include attributes of GHG reduction efficiency, financial feasibility, technology readiness, risk and uncertainty, and community and industrial acceptance. 


\section{INTRODUCTION}

During the last century, the global surface temperature increased $0.74 \pm 0.18$ C (1.33 \pm 0.32 F) (IPCC, 2007b), which is due to a serious problem usually referred as Climate Change or Global Warming. In the US, total greenhouse gas emissions have risen by $17 \%$ from 1990 to 2007 and reached 7,150.1 Million Metric Tons of carbon dioxideequivalent (MMTCO2-eq) in 2007. This represents a $0.6 \%$ increase $(41.5$ MMTCO2-eq) from the 2005 emission level (EPA, 2009).

Various global efforts have been made to mitigate greenhouse gas emissions and adapt to climate change resulting from global warming. In December 2009, the United States officially pledged at the Copenhagen Climate Summit to cut its greenhouse gases emissions from the 2005 level by $17 \%$ by $2020,42 \%$ by 2030 , and $83 \%$ by 2050 . Many state and local governments have adopted even more aggressive reduction targets to tackle climate change. For example, Assembly Bill 32 passed in 2006 requires the state of California to reduce greenhouse gas emissions by $25 \%$ by 2020 (CARB, 2006). Similarly, in Maryland, the Greenhouse Gas Emissions Reduction Act of 2009 sets the target at $25 \%$ below 2006 levels by 2020. (MDE, 2009) Therefore, there is a need for different government agencies to incorporate climate change and sustainability issues into their usual practice in order to meet the ultimate goal in the long-run.

Highway construction is an interindustry field related to both the construction and transportation sectors. Although highway construction is typically considered as being emission intensive (Truitt, 2009), it is not usually addressed as the major greenhouse gas emission source from either the construction or transportation industry. Most of the regulations and initiatives of transportation agencies are regarding emission reduction from on-road operations, and that of construction agencies are mostly considering the building industry. After all, highway construction has its unique features compared with on-road sources or buildings. However, very few studies have been focused on greenhouse gas emissions from the whole life cycle of highway infrastructure development and construction. There are only few comprehensive studies to explore the strategies to integrate emission reduction and sustainability into highway project planning and the delivery process.

This paper is aimed to investigate various contracting strategies for tackling climate change in highway construction projects. The paper briefly reviews the emission sources of highway construction projects on a life cycle basis, and then defines a specific system called Green Performance Contracting (GPC) strategies for highway projects. A previous survey of 39 state Departments of Transportation is referred to regarding the current state of practice and implementation of the strategies. Furthermore, the paper identifies key evaluation criteria used to integrate green contracting strategies into the existing project management system, including GHG emission reduction efficiency, financial feasibility, implementation readiness, risk and uncertainty, community and industrial acceptance. Finally, a Data Envelopment Analysis (DEA) model is proposed to integrate the evaluation and assist state highway agencies in better incorporating green and sustainability into their project delivery processes.

\section{Emissions from Highway Construction}

The transportation sector is the second largest source of carbon dioxide in the U.S. and accounts for almost $30 \%$ of carbon emissions, which is only $5 \%$ lower than that of electricity generation. Meanwhile, it is the fastest-growing source of GHGs. The EPA's analysis for GHG emission of end-use economic sectors indicates that the transportation sector's emissions were around $24 \%$ greater in 2003 than in 1990 , which is much higher than the average U.S. GHG emission net increase of 13 percent over the same time (EPA, 2006)

Related to highway construction, most $\mathrm{CO}_{2}$, methane, and $\mathrm{N}_{2} \mathrm{O}$ emissions are from transportation fossil fuel combustion, which includes petroleum combustion (for light-duty trucks and workers' commuter cars) and diesel combustion (for heavy-duty trucks and off-road construction equipment). Other fluorinated gas emissions are from facility air conditioners and lubricants from vehicle engine combustion.

The common methods used to reduce emissions from these sources recommended by the EPA and FHWA are intended to reduce either fossil fuel usage or emissions from fuel combustion. Available technologies include: increasing engine efficiency using fuel substitutions like biodiesel, installing retrofit devices to filter chemical emissions, or adding additives into fuel to reduce GHG generation. Meanwhile, transportation infrastructure is vulnerable to predicted changes in sea levels, increasingly severe weather, and extreme high temperatures. Long-term transportation adaptation will need to be considered in the early stages of design and construction. Although the construction sector contributes a smaller portion of the U.S. GHG emissions than the transportation industry does, it ranks as the third-highest emission source among end-use industry sectors. According to the EPA's report, in 2002, 131 MMTCO2eq were produced by construction site activities, which represents about $6 \%$ of U.S. industrial GHG emissions, or $1.7 \%$ of total U.S. emissions (EPA, 2008). Within the 131 MMT of carbon emissions by the construction industry, $76 \%$ results from fossil fuel combustion, which overlaps with the transportation sector. The remaining 
$24 \%$ comes from purchased electricity, which is the quantity of GHGs resulting from the generation of purchased electric power.

Specifically for highway construction projects, in order to reduce materialrelated GHG emissions, common practices are to reuse or recycle available industrial materials in the landfill or pavement process. This method can reduce the GHG emissions from the material disposal process and emissions during the manufacturing stage of virgin materials. For emissions from purchased electricity use, it is recommended to employ efficient electrical equipment, such as LEDs for lighting and signals. It is also a growing trend that renewable energy facilities prefer solar panels and wind turbines to be built on highway right-of-ways to generate energy for highway electricity use.

Another important field for highway projects to address climate change is the life-cycle construction planning. For example, more and more requests for proposals (RFP) are requiring contractors to conduct project evaluations for the environmental or community impact. Regulations, such as the Work Zone Safety and Mobility Rule (FHWA, 2004), are also put forward to minimize the GHG emissions generated by traffic congestion because of construction projects.

\section{Green Performance}

\section{Contracting (GPC) Strategies}

For the building sector, Leadership in Energy \& Environmental Design (LEED) is an internationally recognized green certification system which intends to enhance the environmentally responsibility of building operations and efficiency of resource usage. However, there are no universally agreed-upon definitions of what "going green" or sustainability means for highway construction projects, nor is there a clear definition of green contracting for highway project delivery. (Molenaar, et al., 2009) evaluated the performance of various project delivery methods (design-build, design-bid-build, and construction manager at risk) in delivering LEED certified building projects. (Klotz, Horman, \& Modenschatz, 2007) proposed a detailed modeling protocol for evaluating the delivery processes of green projects. However, green project delivery remains undefined.

Many organizations use the triple bottom line of economic, environmental, and social aspects to measure "being green" and sustainability. Similar to this approach, green performance contracting in highway projects could be examined through three configuration scopes. Green performance contracting, then, is defined as any contract provisions, contracting methods, and delivery strategies that help to:

1. Reduce emissions and improve adaptation to climate change (scope 1);

2. Benefit the environment at large (scope 2); or

3. Improve the quality of life of the public through a direct economic, ecological, or social benefit (scope 3). The research objectives for this paper focus on the green performance contracting strategies within the scope covering contracting strategies related to GHG emissions and climate change. Such strategies should contribute to GHG emission reductions throughout the life-cycle of a project. Specifically, emission reductions should target: upstream material processing and transportation; construction site equipment operations and energy use; facility operation and maintenance; and finally demolition.

A number of contracting strategies either have been or could be incorporated into highway construction. These strategies directly or indirectly contribute to emission mitigation and/or climate change adaptation. For example, diesel engine retrofit and use of alternative fuels in construction equipment would reduce the consumption of fossil fuels, which directly lowers emissions from highway construction operations.
Use of reclaimed asphalt pavement reduces the demand for virgin materials and limits energy use and emissions resulting from the production and delivery of virgin materials.

In accordance with applied project phase and emission sources addressed by the strategies, the green performance contracting strategies can be classified into four levels:.

1. Level I: Material Related Strategies Material Related Strategies are the most common green methods utilized in the highway construction process. Although the original incentives are mainly based on the cost saving perspective instead of the climate change concern, the effect of greenhouse gas emission reduction using the material related strategies is substantial.

Material Related Strategies mainly include:

- Material Recycling or Reusing, which takes advantage of industrial byproducts or recycled materials, such as reclaimed asphalt, recycled concrete, fly ash, etc., as substitutions for raw materials during construction. These strategies can reduce the GHG emission during material disposal and virgin material manufacturing.

- Material Treatment, which basically controls the GHG emissions directly from the material treatment process and future operation phase or indirectly related to the energy use in material treatment. Typical strategies include warm/cool pavement, concrete additives, light aggregate in concrete pavements, etc.

- Material Life Cycle Management, which refers to the whole life cycle of materials as they flow through the process of selection, production, procurement, shipment, recycling/reusing, and disposal. These strategies are usually conducted with different software and tools, such as the shipment model FLEET (EPA), pavement life-cycle assessment tool PaLATE (Horvath, 2007), and material life cycle tool BEES (DOE, 2008). 
2. Level II: Equipment and Energy Efficiency Strategies

Emission from fuel combustion is the largest GHG emission resource of the transportation and construction industries. In order to reduce the fuel combustion emission, renewable equipment devices and efficient fuel use are two important categories for highway construction projects.

For example, contractors could be regulated or incentivized to adopt engine retrofit according to EPA (EPA, 2000) or CARB (CARB, 2002) verified technologies, using repowering and upgrading engines or better selecting their equipment. Alternatively, construction companies could also be required to use alternative fuels for their equipment, to reduce equipment idling, or to implement Work Zone Mobility management.

3. Level III: Green Life Cycle Strategies In businesses, Life-Cycle Management (LCM) has been developed as an approach for managing the total life cycle of products and services. It addresses a broad range of activities, starting with the initial identification of the problem, processing through the building or acquisition of a solution, and ending with the final disposition of the solution at the end of its useful life (EPA, 1989). Similarly, green life-cycle strategies for highway projects should be a framework used to target, organize, analyze, and manage project-related information and activities toward continuous sustainable improvement along the project life cycle. A particular strategy could help to:

- Analyze and understand the environmental issues of the different lifecycle stages of the project.

- Identify the potential environmental, economic, and social risks, as well as the potential sustainability opportunities at each stage.

- Establish proactive systems to pursue the opportunities and manage or minimize the risks.
4. Level IV: Clean Energy Development

\section{Strategies}

A clean energy development strategy involves innovative thinking through infrastructure design, project partnerships, financing methods, construction techniques, evaluation methodologies, delivery processes, and future maintenance. For highway construction, clean energy technologies are in the very early stage of development, but there have been some successful cases in the electricity generation and agriculture sectors where the implementation process and technologies could be borrowed.

\section{State of Practice of GPC in United State}

From April to June 2010, Departments of Transportation (DOTs) of all U.S. states and Washington DC were surveyed about their practices of using green performance contracting in highway development and construction projects. For the 39 DOTs that responded, the survey report identified and evaluated their practices for managing climate change and sustainability at the highway project level (Cui \& Zhu, 2011).

Figure 1 is a summary of the nationwide practice of GPC. All 39 reported states have used Level I strategies, particularly using recycled materials in highway construction. There are total 12 states that have implemented at least one Level II green strategy in addition to Level I strategies. California, Illinois, New York, Oregon, and Washington have integrated green road rating or energy and emission analysis (Level III strategies) into their highway project development processes. Lastly, Oregon DOT developed its first solar highway project in 2008 and continues to expand the installation of solar panels in the highway right-of-way to generate power for highway lighting (Level IV strategy).

Level I strategies have been widely used in highway projects; however, implied by the survey responses, the main reason for adopting these strategies, especially for reused or recycled materials, are not for the sustainability concern, but instead driven by cost. The typical implementations for such materials are mainly proposed by construction companies, and then transportation agencies evaluate the feasibility, environmental suitability, and expected performance before adopting the strategies (Collins \& Ciesielski, 1993). Sometimes agencies will regulate a certain percentage ceiling based on their research, or they will refer to FHWA's guidelines (FHWA, 1994). Some states also have on-going efforts on standardizing the Level I strategy adoption. For example, Wisconsin DOT continues to re-write its contract standard specifications as "performance-based specifications", facilitating the use of recycled materials to the maximum extent possible in their highway construction projects (Wisconsin DOT, 2006).

There are 12 states that have implemented at least one Level II strategy in addition to Level I strategies. Among all Level II strategies, 10 states adopted idling reduction policies, 9 utilized alternative fuels, 7 launched engine retrofit programs, and 4 established energy efficiency programs. These strategies, on the other hand, are expected to result in incremental costs in project construction and therefore need extra organizational support through agency initiatives, regulations, or even legislations. Most states DOTs established air quality programs in the early 9o's to assess and address the construction-related emissions, including ROG, NOX, PM, etc. Therefore, some state DOTs (e.g. New York, Oregon, Washington) address the impact for climate change by incorporating GHG emissions into the existing program and update their evaluation process. Some other states establish new initiatives or programs to promote the Level II strategies. Missouri DOT established its green initiative program to award 


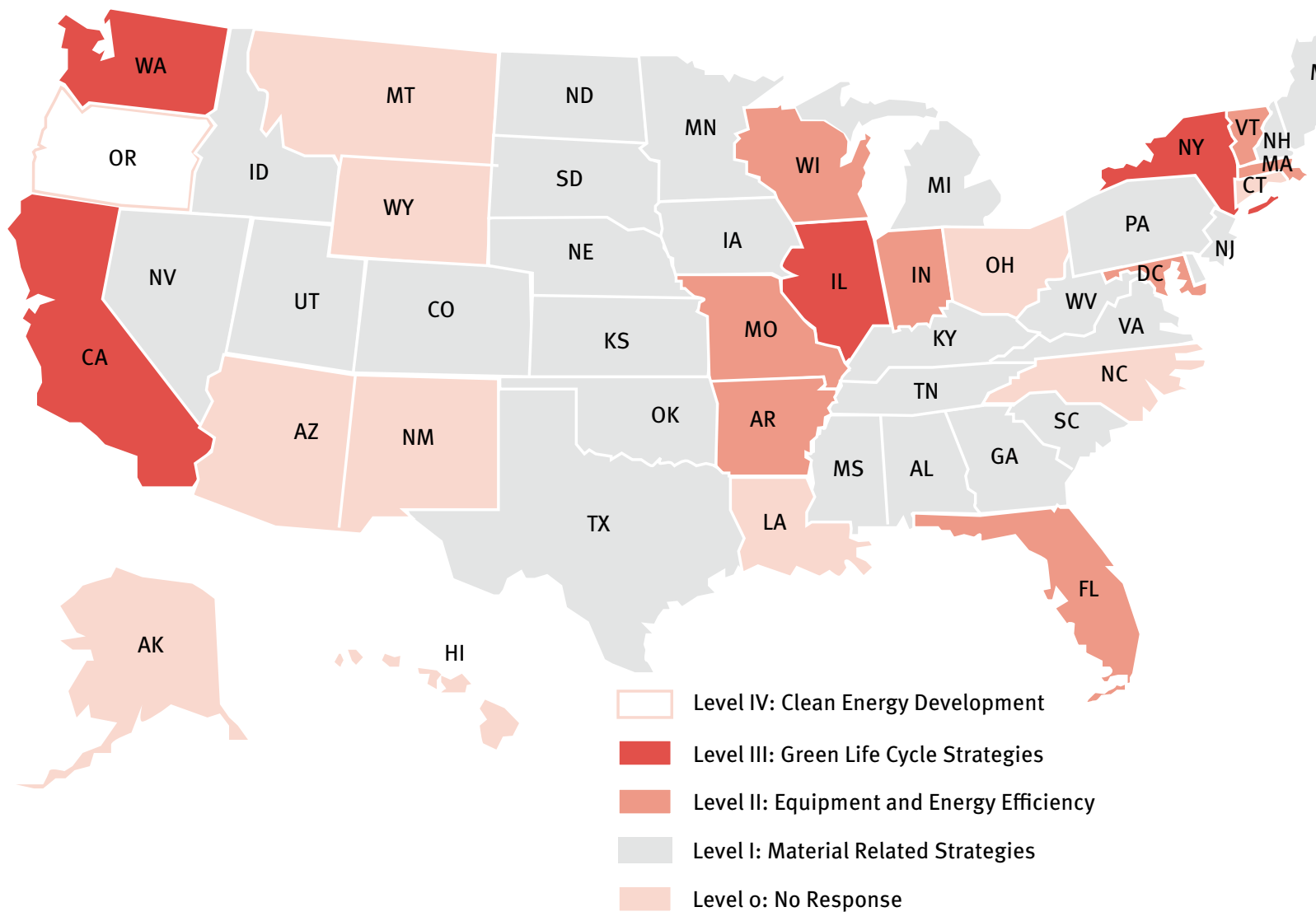

Figure 1 State DOTs GPC Practice for Highway Projects (Cui \& Zhu, 2011)

green contractors. Under this program, the agency assigns a "green credit" goal for the contractor and appoints a "green credit" value for the use of various environmentally friendly practices, including alternative fuels and retrofit technologies. The California Air Resources Board (CARB) proposed a Low Carbon Fuel Standard Program (LCFS) that will reduce greenhouse gas emissions by reducing the full fuel-cycle carbon intensity of the transportation fuel pool used in California (CARB, 2005). In Vermont, besides the green initiative within the highway agency, a state climate change commission was established three years ago by the governor to both promote energy efficiency and create a "Green Standard" for pricing carbon reduction efforts.

Five responding states (CA, IL, NY, OR, WA) have adopted Level III strategies used in the areas of project lifecycle emission, energy analysis and green highway rating. Their strategies are entirely driven by state policies and legislations. In New York, the State Energy Plan requires the state DOT to conduct a greenhouse gas energy analysis on its transportation plans. In Washington, Executive Orders 05-01, 04-01, and 02-03 direct Washington DOT to develop Sustainability Plans that report on sustainable business practices and track progress. In Illinois, along with agency's green initiative, an office of sustainable practice was established to guide the agency's sustainable practice in the areas of planning, design, construction, maintenance, operations, and others.

Also associated with Level III strategies is the green highway rating system. The survey identified three rating systems currently used in the U.S., namely, GreenLITES, Greenroads, and I-LAST. The Green Leadership in Transportation Environmental
Sustainability (GreenLITES), endorsed by New York State DOT, requires all project Plans, Specifications \& Estimates (PS\&Es) submittals to be GreenLITES certified. Greenroads was developed by the University of Washington and Ch2MHILL, and has been used for evaluating several pilot projects in Washington and Oregon. The IlliniosLivable and Sustainable Transportation (I-LAST) rating system is also voluntary in nature. The purpose, according to Illinois DOT, is to provide a list of best practices to bring sustainability to highway projects.

For the Level IV strategy, Oregon DOT developed its first solar highway project in 2008 and continues to expand the installation of solar panels in the highway right-of-way to generate power for highway lighting. Although other states have not yet addressed Level IV strategies in highway projects, many efforts are underway. The 
Massachusetts Turnpike Authority is currently building a wind turbine near the turnpike rest area. The Maryland SHA also installed a wind turbine in 2009 to power an agency facility. Several state DOTs (e.g. CA, IL, MI) are pursuing federal grants for renewable energy projects, including green rest areas and solar powered interchanges.

\section{Strategy Evaluation and Selection}

Based on the preceding review of existing models for green and sustainable performance contracting, it is clear that although the specifics of some standards converge, there still is no widely agreed-upon standard. An evaluation tool is needed to assist highway agencies in selecting the appropriate green performance contracting (GPC) strategy or portfolio of strategies. First, the GPC strategies identified in the previous chapters address diverse emission sources, impose distinct contract requirements, result in unequal implementation costs, and yield varied environmental benefits. It is obvious that some strategies are complementary to others, while others are competitive or mutually exclusive. Second, a state highway agency has to operate within the constraints of its existing capacity including authority, cost, and staffing. Furthermore, other factors, such as organizational complexity and industrial acceptance, also play an important role in the successful implementation of GPC strategies in highway construction projects. Given limited resources and budgetary constraints, the agency should determine an optimal strategy portfolio that offers the maximum benefit at the lowest cost and risk.

When considering the features and characteristics of a problem, the decision-making model must be well designed to satisfy internal organizational requirements, integrate both qualitative and quantitative data, and remain flexible to new advances. After all, highway agencies show vastly different levels of experience on innovations and emission management. In this research, a Data Envelopment Analysis (DEA)-based decision-making model was developed to evaluate the efficiency of GPC strategies in terms of yielding the maximum benefits at the lowest costs (tangible and intangible). The model follows a four-stage process to select a portfolio of relative efficient GPC strategies among all possible strategies (Figure 2).

\section{Evaluation Criteria}

Seven evaluation criteria were identified and defined in the decision-making model, namely, emission reduction potential, financial consideration, technological maturity, organizational readiness, industrial and public acceptance, risk, and impact on project performance. These criteria are discussed below and an assessment is made thereafter.

\section{1 / Emission Reduction Potential}

An agency needs to evaluate the potential of GPC strategies to reduce GHG emissions both in the short and long terms. Some strategies can be adopted immediately without considerable investments or major process change, but their potential to contribute to the reduction target is limited. The potential of clean energy development and other strategies seems promising, but the high cost and requirement for major process changes make them hard to be easily implemented. Issues should be considered in this category include the following:

$\checkmark$ Emission reduction target

Existing emission inventory

Emission type, source, and volume addressed by GPC strategies

$\checkmark$ Long term emission reduction due to GPC strategies

$\checkmark$ Emission reduction estimation method and accuracy, and

Application condition

\section{2 / Financial Consideration}

Cost of implementation is one of the driving factors behind the desire to select appropriate GPC strategies in highway project construction. The financial consideration encompasses all direct and indirect costs associated with the implementation of a GPC strategy, as well as the availability and accessibility of external financial resources. Implementation costs cover activities as varied as the acquisition and installation of engine retrofit devices to the entire project. One should note that the implementation costs are calculated from a project life-cycle perspective. If a GPC strategy incurs additional costs during project operation and maintenance, those incremental costs should also be considered. It is also important to note there are numerous federal and state programs to encourage the use of green technologies and clean energy. Some GPC strategies may also create valuable emission credits that are tradable in the market. These government and market incentives are important determinants influencing the adopting large scale and costly green strategies, as they can dramatically reduce the total implementation cost. Issues that should be assessed include:

- Implementation costs, e.g.: new materials and equipment, labor and other resources, development and evaluation, additional administrative and overhead costs, transaction fees, relevant consulting and legal services, and changes in organization and management systems

> Other incremental costs over the project life cycle and associated with GPC strategies

Benefits associated with the implementation, e.g.: savings in labor and materials, less energy consumption, or less transaction fees.

- External Financial Resources, e.g.: Federal and state grants, low interest credit assistance, tax incentives, renewable energy credit, or carbon reduction credits.

ther cost items 


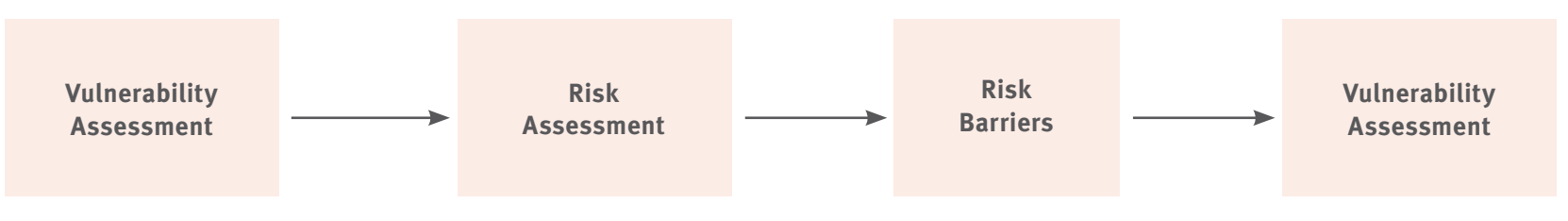

Figure 2 DEA Efficiency Evaluation Process

\section{3 / Technological Maturity}

Technological Maturity refers to the theoretical, technical, and practical issues of the strategies during implementation. Technological maturity is a method of evaluating whether a GPC strategy and its underlying technology are functional and ready for immediate implementation by a highway agency. Some technologies are mature and ready for commercial use, while others are under development or in pilot phase and hence require a relatively long duration for implementation. Because climate change-related technologies continue to evolve, it is critical to continually updating the analysis of technological maturity with new data and applications. Issues covered in this category include:

- Underlying technologies

Technology effectiveness and efficiency

- Acceptance and popularity

- Availability of commercial products

Dest practices

$\checkmark$ Learning curve

- Concerns and risks

\section{4 / Organizational Readiness}

The implementation of GPC strategies typically requires changes in organizational structure, innovation in business processes and operations, and evolution of regulations and specifications. For example, an agency may need to establish a specific task team, launch new initiative or program, or redevelop standard construction specifications to implement certain GPC strategies. Organizational readiness describes how likely it is that an organization can successfully incorporate new GPC strategies into its business operations. To evaluate organizational readiness, one should consider the following items.

Existing green initiatives and programs

Organization structure and complexity

- Current contract standards, conditions, and specifications

Project delivery systems and processes

- Consultancy availability

Project Management.

\section{5 / Industrial and Public Acceptance}

The successful implementation of the strategies depends on close collaboration between public agencies and the construction industry. The reactions from local communities may also play an important role in the acceptance of certain GPC strategies because many of the strategies directly influence the quality of life. Therefore, the implementation of these strategies will be strongly dictated by the local communities and special interest groups. Public outreach efforts regarding sustainable or green practices in transportation projects may also create a positive public image for the organization. The following issues should be considered when evaluating the industrial and public acceptance.

\section{- Market conditions and} competitiveness

- Industrial structure and contractor profile

- Opinions from professional associations and private companies

- Public awareness and opinions

Outreach efforts and public involvement

\section{6 / Impact on Project Performance}

Adoption of GPC strategies may affect a project's cost, schedule, or overall performance. Some strategies may provide positive outcomes by encouraging energy efficiency, or by using low-cost recycled materials. Other strategies require extensive time and cost for contractors to ensure compliance with regulations and specifications, and, hence, pose a significant potential conflict with other project objectives. An agency should recognize and balance competing project objectives while selecting appropriate GPC strategies for highway construction. Issues to be considered regarding project performance include:

> Project objectives and priority

$\checkmark$ Performance evaluation method

- Impact of GPC strategies on project delivery process

$\checkmark$ Impact of GPC strategies on project time and cost

- Impact on compliance inspection

Other aspects of project performance, e.g. safety, environment, etc.

\section{7 / Risk and Uncertainty}

The implementation of GPC strategies is an agency-wide endeavor with significant risk and uncertainty. The risk stems from various factors that include, but are not limited to, technical failures, institutional resistance, market volatility, and public suspicion. Overstated GHG emission reductions, underestimated implementation cost, and inaccurate assessment of project performance impacts can also pose significant challenges for a highway agency to optimize strategy selection and decision making. The agency should evaluate the reliability and 


\begin{tabular}{|c|c|c|c|c|c|c|c|}
\hline Score & $\begin{array}{c}\text { Financial } \\
\text { Consideration }\end{array}$ & $\begin{array}{c}\text { Technological } \\
\text { Maturity }\end{array}$ & $\begin{array}{l}\text { Organizational } \\
\text { Readiness }\end{array}$ & $\begin{array}{c}\text { Industrial and Public } \\
\text { Acceptance }\end{array}$ & $\begin{array}{l}\text { Emission } \\
\text { Reduction }\end{array}$ & $\begin{array}{c}\text { Impact on } \\
\text { Project } \\
\text { Performance }\end{array}$ & Risks \\
\hline 1 & $\begin{array}{l}\text { Cost Effective/ } \\
\text { significant } \\
\text { benefits }\end{array}$ & $\begin{array}{l}\text { Practiced by } \\
\text { the Agency }\end{array}$ & $\begin{array}{l}\text { Completely } \\
\text { Prepared }\end{array}$ & $\begin{array}{l}\text { Completely } \\
\text { Acceptable }\end{array}$ & Great Extent & Highly Positive & Low Risk \\
\hline 2 & $\begin{array}{c}\text { Little or } \\
\text { Negligible } \\
\text { Effectiveness }\end{array}$ & $\begin{array}{l}\text { Slightly } \\
\text { Different } \\
\text { Practice }\end{array}$ & Mostly & $\begin{array}{l}\text { Somewhat } \\
\text { Acceptable }\end{array}$ & Much & $\begin{array}{l}\text { Somewhat } \\
\text { Positive }\end{array}$ & $\begin{array}{l}\text { Some } \\
\text { Risks }\end{array}$ \\
\hline 3 & $\begin{array}{l}\text { Slightly Cost } \\
\text { Ineffective }\end{array}$ & $\begin{array}{l}\text { Practiced by } \\
\text { Others }\end{array}$ & Somewhat & Neutral & Somewhat & Negligible & Risky \\
\hline 4 & Cost Ineffective & $\begin{array}{l}\text { Limited Use by } \\
\text { Others }\end{array}$ & Minimally & Somewhat Concerned & Very Little & $\begin{array}{l}\text { Somewhat } \\
\text { Negative }\end{array}$ & $\begin{array}{l}\text { Very } \\
\text { Risky }\end{array}$ \\
\hline 5 & $\begin{array}{l}\text { Highly Cost } \\
\text { Ineffective }\end{array}$ & $\begin{array}{c}\text { New } \\
\text { Technology }\end{array}$ & Not At All & Serious Problem & Not At All & Highly Negative & High Risk \\
\hline
\end{tabular}

\section{Table 1 Five-Point Likert Scale for the Evaluation Criteria}

robustness of GPC strategies under uncertain conditions. The evaluation should cover the following issues.

- Technical, organizational, market risks

- Inaccuracy in emission reduction estimation

- Low industrial capacity and competition

Specification, manual, and guidance related risks

Policy and regulation change

\section{Evaluation Method}

The decision model for identifying appropriate GPC strategies is based on the Data Envelopment Analysis (DEA) technique. The DEA technique is a non-parametric linear programming approach that produces a single measure of efficiency for each evaluation unit (called decision making unit or DMU) relative to its peers (Cook \& Zhu, Rank order data in DEA: A general framework., 2006). DEA technique was first proposed in the microeconomic production theory to measure a firm's production efficiency (Charnes, Cooper, \& Rhodes, 1978). While applied in the operations management domain, the core idea of the methodology is to identify a portfolio of strategies whose input-output efficiencies are maximized and indifferent.

In this study, the DEA analysis is proposed to evaluate the efficiency for different GPC strategies, where the GPC strategies are defined as the DMUs in the model. We take the evaluation criteria as the variables for the DEA model. In specific, the input are: Financial Consideration, Technological Maturity, Organizational Readiness, and Industrial and Public Acceptance; and the output are: Emission Reduction, Impact on Project Performance, and Risks. Since the criteria are mostly based on the expert judgment of different strategies, a five-point Likert scale is then utilized to generate a score card for agency's use.

Once the information are collected from the agency, a DEA optimization model is then built to calculate the relative input-output ratio of each strategy

\begin{tabular}{|c|c|c|c|c|c|c|c|}
\hline & \multicolumn{4}{|c|}{ Input } & \multicolumn{3}{|c|}{ Output } \\
\hline Strategy & $\begin{array}{c}\text { Financial } \\
\text { Consideration }\end{array}$ & $\begin{array}{l}\text { Technical } \\
\text { Implementation } \\
\text { Readiness }\end{array}$ & $\begin{array}{c}\text { Organizational } \\
\text { Readiness }\end{array}$ & $\begin{array}{l}\text { Industrial } \\
\text { and Public } \\
\text { Acceptance }\end{array}$ & $\begin{array}{c}\text { GHG } \\
\text { Reduction } \\
\text { Potential }\end{array}$ & $\begin{array}{l}\text { Impact on } \\
\text { Project } \\
\text { Performance }\end{array}$ & Risks \\
\hline L1-01 & & & & & & & \\
\hline L1-02 & & & & & & & \\
\hline L1-03 & & & & & & & \\
\hline$\ldots$ & & & & & & & \\
\hline L3-03 & & & & & & & \\
\hline L4-01 & & & & & & & \\
\hline $\mathrm{L} 4-02$ & & & & & & & \\
\hline
\end{tabular}

Table 2 GPC Strategy Scorecard Template 


\begin{tabular}{|c|c|c|c|c|c|c|}
\hline $\begin{array}{c}\text { Financial } \\
\text { Consideration }\end{array}$ & $\begin{array}{c}\text { Technical } \\
\text { Implementation } \\
\text { Readiness }\end{array}$ & $\begin{array}{c}\text { Organizational } \\
\text { Readiness }\end{array}$ & $\begin{array}{c}\text { Industrial } \\
\text { and Public } \\
\text { Acceptance }\end{array}$ & $\begin{array}{c}\text { Emission } \\
\text { Reduction } \\
\text { Potential }\end{array}$ & $\begin{array}{c}\text { Impact on } \\
\text { Project } \\
\text { Performance }\end{array}$ & Risks \\
\hline 1 & 1 & 2 & 1 & 4 & 2 & 1 \\
\hline
\end{tabular}

(RAP)

L1-02 Other Material

Recycling or Reusing

L1-03 Sustainable

Material Treatment

2

3

4

2

L1-04 Material Waste

Management

L1-05 Material LifeCycle Management

L2-01 Equipment

Retrofit Technology

L2-02 Engine

Repower and

Upgrade

$+2$

2

2

2

3

L2-03 Idling

Reduction

3

2

3

3

L2-04 Alternative Fuels

4

4

4

4

3

3

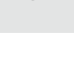

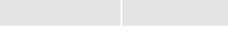

\begin{tabular}{|c|c|c|c|c|c|c|}
\hline 4 & 1 & 1 & 4 & 2 & 3 & 2 \\
\hline 5 & 2 & 1 & 5 & 2 & 3 & 2 \\
\hline
\end{tabular}

L2-05 LED Lighting

II

L2-06 Equipment
Operation and
Maintenance
Management
L2-07 Equipment
Selection
and Vehicle

Electrification

2

L2-08 Work Zone
Traffic Management

2

2

4

3

2

$-1$

12

4

3

2

2

3

\begin{tabular}{l|l}
2 & 2
\end{tabular}

d

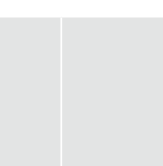

4

2

2

2

$4 \quad 3 \quad 2$

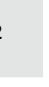

4

\section{L2-09 Employee \\ Commuting}

Reduction

L3-01 Green Road Rating System

III
L3-02 Climate Impact Analyses

$\sqrt{2}$

3

3

1
4

3

\begin{tabular}{l|l|l} 
L3-03 Climate & \\
Adaptation Design & 5 \\
\hline
\end{tabular}

\begin{tabular}{|c|c|c|c|c|c|c|c|c|}
\hline \multirow{2}{*}{ IV } & $\begin{array}{l}\text { L4-01 Highway- } \\
\text { related Solar Energy }\end{array}$ & 5 & 4 & 4 & 3 & 1 & 4 & 4 \\
\hline & $\begin{array}{l}\text { L4-02 Highway- } \\
\text { related Wind Turbine }\end{array}$ & 5 & 4 & 5 & 3 & 1 & 4 & 5 \\
\hline
\end{tabular}




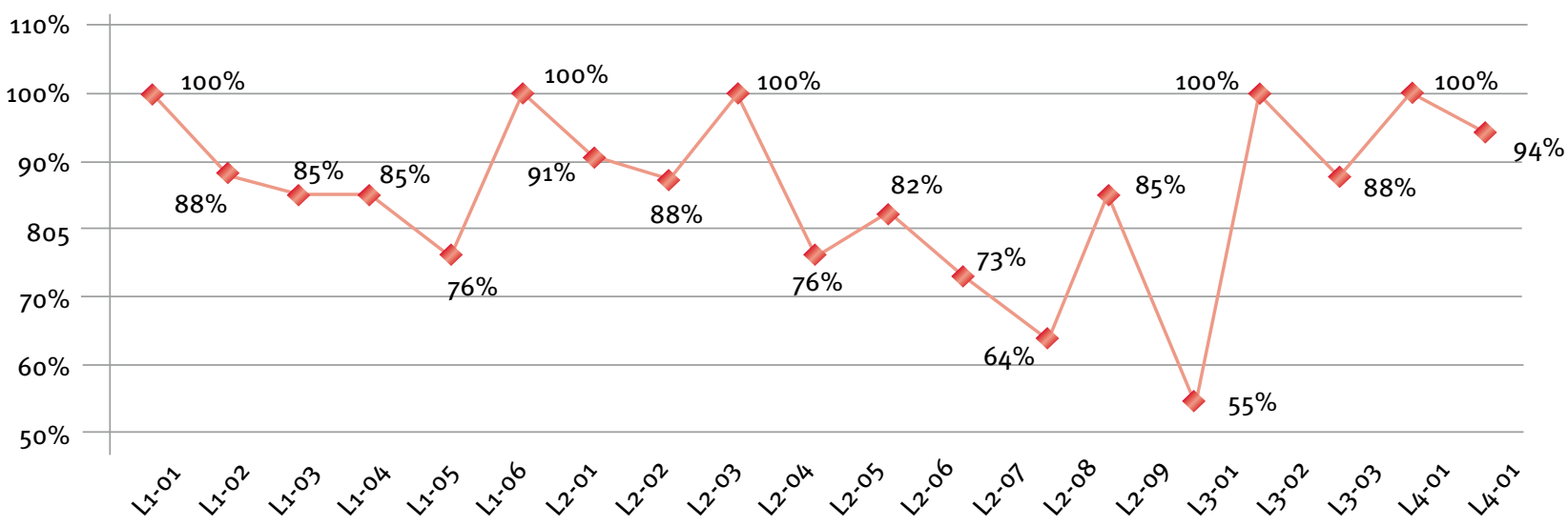

Figure 3 GPC Strategy Efficiency

comparing with others. With the model, the efficiency frontier could be obtained to assist the highway agency to select the most efficient strategies as their green contracting portfolio and get the highest expectation for their sustainability performance.

\section{Strategy Scorecard}

An analyst or an expert group first collects data and tabulates statistics by strategy and evaluation criteria in a consistent manner. Both numeric and plain-text data should be included in this step. One could use numeric data directly in the DEA analysis or use rating scales that embrace both numeric data and plain-text information regarding GPC strategies. A five-point Likert scale is a preferred method in this study. Score may range from the most favorable rating $(=1)$ to least favorable rating $(=5)$. Detailed definition of the five-point Likert scale for each GPC evaluation criterion is described in Table 1. Then all assigned ratings should be tabulated in the GPC strategy scorecard. A sample GPC strategy scorecard template for practical use is provided in Table 2.

\section{Efficiency Assessment}

After the scorecard is completed, one can apply the DEA decision model to calculate the efficiency frontier of all GPC strategies. The basic idea of the
DEA decision model is to find the set of GPC strategies that form a frontier surface that represents all evaluation criteria. This envelopment surface is referred to as the efficiency frontier. The efficiency of each GPC strategy is determined based on a comprehensive analysis of measuring the distance to the efficiency frontier.

It is worthy noted that the classic DEA model is assumed to deal with the input and output as quantitative factors (Charnes, Cooper, \& Rhodes, 1978). With the development of the model applied in less precise environment, many researches modified the model to incorporate rank order data (Cooper, Park, \& Yu, 1999; Cook W. K., 1993), for example, in terms of Likert scale (Cook \& Zhu, 2006; Cook, Kress, \& Seiford, 1996). In this paper, the model formation of (Cook, Kress, \& Seiford, 1996) will be referred as the mathematical model of DEA with Likert Scale variables.

The DEA decision model can be solved with optimization software packages, e.g. DEAFrontier, Excel Solver, or Matlab. The solution will be a set of efficiency rankings in the form of percentage. The efficiency ranking measures the efficiency of a certain strategy compared to other strategies with regard to all seven criteria. A score of $100 \%$ indicates a GPC perfectly aligns with the highway agency's criteria and is highly efficient. If a GPC strategy is rated below $100 \%$, the strategy is less efficient compared to other strategies.

\section{Case Study: Maryland State Highway Administration Sustainability Strategy} The State of Maryland has developed a climate action plan calling for dramatic GHG emissions reductions from the transportation sector. Given various strategies at the project level, the Maryland State Highway Administration (MDSHA) needs to understand the potential of each strategy in terms of effectiveness and efficiency to achieve the emission reduction target at the lowest cost and risk. The framework of the Green Performance Contracting proposed in this paper was used to evaluate all sustainability strategies for implementation. The evaluation was assumed to be conducted during the project development phase with relevant information collected including:

MDSHA business plan and organizational structure

- Project development manual, standards, and specifications

- Emission inventory and climate action plan implementation status

$\checkmark$ GPC implementation cost

- Federal and state grants for energy efficiency and green transportation

- Engineers' opinions on implementing GPC strategies 
The scores were determined by the team's understanding and knowledge about existing practices and MDSHA operations. A complete score tabulation is summarized in Table 3. And the evaluation solutions are shown in Figure 3. It should be noted that the DEA decision model can incorporate numeric/ratio data in addition to ordinary Likert scale data used in this case. If such data on GPC strategy implementation cost or estimated GHG emission reduction is available, the analyst could use these numeric cost and emission data directly in the DEA efficiency assessment.

The analysis demonstrated that five GPC strategies provide the maximum emission reduction benefit at the lowest cost and risk (Table 4). These five strategies are found to be efficient as compared to other strategies. These five optimal GPC strategies are indifferent in terms of implementation efficiency.

L1-01 Reclaimed Asphalt Pavement (RAP)

L2-01 Equipment Retrofitting

L2-04 Alternative Fuels

L3-02 Climate Impact Analyses

L4-01 Highway-related Solar Energy

Table 4 Strategy Selection Result for MDSHA

With the suggested result, MDSHA could select one or more of these GPC strategies to satisfy its budgetary and resource constraints. Without an observable increase in project cost, the MDSHA can achieve, for example, a considerable reduction on GHG emissions from construction materials by requiring use of RAP in construction.
The agency can also cut more emissions from construction operations, primarily from equipment operations, by incorporating retrofitting and alternative fuel requirements in the construction specifications. At the project development and planning phase, the agency can conduct life-cycle climate impact analysis so that low-emission design alternatives are identified, evaluated, and selected. This strategy is especially important because it offers an opportunity to reduce emissions and adapt to climate change at the early phase when life-cycle benefits can be realized. The MDSHA should explore opportunities to use renewable energy at its facilities. It is also economic and technically possible to deploy solar energy in maintenance facilities and for roadway lighting.

Other GPC strategies can also be included for supplementary benefits. It should be noted that the strategy assessment and selection is a dynamic process and should be adjusted while new information, knowledge, or strategy is available. The agency should also monitor and evaluate the strategy implementation to improve the decision model and strategy assessment process.

\section{Conclusion}

With the growing awareness of global climate change and the need for sustainability, state highway agencies are taking essential steps to reduce carbon emissions and life cycle impact of highway infrastructure. While many strategies are known to assist highway agencies to mitigate and adapt to climate change during highway operations, little is known about how climate change issues should be integrated into highway planning, delivery, and construction processes.

This paper defines a Green Performance Contracting (GPC) framework with nineteen available green performance contracting strategies that were classified into four levels:

- Level I: Material Related Strategies
Level II: Equipment and Energy Efficiency Strategies

- Level III: Green Life Cycle Strategies

Level IV: Clean Energy Development A survey of the GPC strategies implemented by various state Departments of Transportation (DOTs) is conducted. According to the results of the survey, State DOTs have varying degrees of experience regarding the use of green performance contracting strategies in highway projects.

An evaluation process is then proposed to assist state highway agencies in better assessing the strategies and incorporating green and sustainability principles into their project delivery processes. Seven evaluation criteria are built:

$>$ Emission Reduction Potential

- Financial Consideration

> Technological Maturity

> Organizational Readiness

- Industrial and Public Acceptance

Impact on Project Performance

Risk and Uncertainty

An optimization model based on the Data Envelopment Analysis (DEA) technique is utilized to determine the selection of the portfolio of GPC strategies for the agency, in terms of abovementioned evaluation criteria. Based on an evaluation using a 5-point Likert scale, an efficiency frontier can be identified as the set of the most efficient GPC strategies.

Finally the GPC strategy framework is implemented for the Maryland State Highway Administration as a case study. With the scorecard collected from the agency experts, the following strategies are selected as the most efficient sustainability strategy for the MDSHA. Corresponding recommendations are duly provided.

- L1-01 Reclaimed Asphalt Pavement (RAP),

- L2-01 Equipment Retrofit Technology,

L2-04 Alternative Fuels,

L3-02 Climate Impact Analyses, and

L4-01 Highway-related Solar Energy. 


\section{Acknowledgments}

The authors would like to acknowledge the financial support provided by the Maryland State Highway Administration. Special thanks go to Kirk McClelland, Lisa Choplin, Allison Hardt, and Hua Xiang for their help and advice on the survey design and research direction. Their time and efforts are acknowledged and greatly appreciated.

\section{References}

CARB. (2002). Verified diesel emission control strategies. Retrieved from http://www.arb. ca.gov/diesel/verdev/vt/cvt.htm

CARB. (2005). Regulations to Achieve Greenhouse Gas Emission Reductions, Low Carbon Fuel Standard. Retrieved from http://www.arb.ca.gov/regact/2009/lcfsog/ Icfscombofinal.pdf

CARB. (2006). Assembly Bill 32: Global Warming Solutions Act.

Charnes, A., Cooper, W., \& Rhodes, E. (1978). Measuring the efficiency of decision-making units. European Journal of Operational Research , 429-444.

Collins, R., \& Ciesielski, S. (1993). Recycling and Use of Waste Materials and Byproducts in Highway Construction.

Cook, W. K. (1993). On the use of ordinal data in Data Envelopment Analysis. Journal of the Operational.

Cook, W., \& Zhu, J. (2006). Rank order data in DEA: A general framework. European Journal of Operational Research, 1021-1038.

Cook, W., Kress, M., \& Seiford, L. (1996). Data Envelopment Analysis in the presence of both quantitative and qualitative factors. Journal of the Operational Research Society, 945-953.

Cooper, W., Park, K., \& Yu, G. (1999). IDEA and AR-IDEA: Models for dealing with imprecise data in DEA. Management Science, 597-607.

Cui, Q., \& Zhu, X. (2011). Green contracting in highway construction: State of the Practice. Transportation Research Record: Journal of the Transportation Research Board, 11-18.

DOE. (2008). Material Life Cycle Tool BEES. Retrieved from http://apps1.eere.energy. gov/buildings/tools_directory/software.cfm/ $\mathrm{ID}=176 /$ pagename $=$ alpha_list
Elkington, J. (1998). Cannibals with Forks: the Triple Bottom Line of 21st Century Business.

EPA. (1989). Retrieved from OSWER Life Cycle Management Guidance: http://www.epa. gov/oswer/oswerlcm.htm

EPA. (2000). Verified technologies for engine retrofit programs. Retrieved from http:// www.epa.gov/dieselretrofit/verif-list.htm

EPA. (2006). Greenhouse Gas Emissions from the U.S. Transportation Sector, 1990-2003. US Environmental Protection Agency.

EPA. (2008). Quantifying Greenhouse Gas Emissions from Key Industrial Sectors in the United States. U.S. Environmental Protection Agency.

EPA. (2009). Inventory of US Greenhouse Gas Emissions and Sinks: 1990-2007. US Environmental Protection Agency.

EPA. (n.d.). Transportation Tools. Retrieved from http://www.epa.gov/climatechange/wycd/ tools_transportation.html

FHWA. (1994). The Use of Recycled Materials in Highway Construction. Retrieved from http://www.fhwa.dot.gov/publications/ publicroads/94fall/p94au32.cfm

FHWA. (2004). Rules and Regulations: Work Zone Safety and Mobility. Federal Highway Administration.

Horvath, A. (2007). Pavement Life-cycle Assessment Tool for Environmental and Economic Effects. Retrieved from http:// www.ce.berkeley.edu/ horvath/palate.html

IPCC. (2007b). Climate Change 2007: The Physical Science Basis. Intergovermental Panel on Climate Change.

Klotz, L., Horman, M., \& Modenschatz, M. (2007). A Lean Modeling Protocol for Evaluating Green Project Delivery. Lean Construction Journal, 3(1).

MDE. (2009). GREENHOUSE GAS REDUCTION ACT OF 2009 BILL SUMMARY. Maryland Department of Environment.

Molenaar, K., Sobin, N., Gransberg, D., McCuen, T., Korkmaz, S., \& Horman, M. (2009). Sustainable, High Performance Projects and Project Delivery Methods: A State-of-Practice Report. Charles Pankow Foundation.

Truitt, P. (2009). Potential of Reducing Greenhouse Gas Emissions in the Construction Sector. US Environmental Protection Agency, February 2009, Washington DC.

Wisconsin DOT. (2006). Beneficial Use of
Industrial Materials and Recycling in Wisconsin DOT Projects. Retrieved from http://www.epa.gov/osw/conserve/rrr/imr/ pdfs/wiscon1.pdf 